\title{
Gender in Audio-visual Advertisements in Ghana: A Semiotics Analysis
}

\author{
Daniel Edem Adzovie' ${ }^{1}$, Rita Holm Adzovie ${ }^{2,}{ }^{*}$ and Enoch Boateng ${ }^{3}$ \\ ${ }^{1}$ Tomas Bata University, Czech Republic and University of Cape Coast, Ghana \\ ${ }^{2}$ University of Cape Coast, Ghana \\ ${ }^{3}$ National University of Science and Technology "MISIS"
}

\begin{abstract}
.
Advertisements, no matter the form, are ubiquitously part of our daily lives and these advertisements carry meanings. Advertisements are open to be read as text wherever they are published in the digital space. The authors examine how gender is presented in Adonko bitters audio-visual advertisement (ad) in Ghana. Rolland Barthes' concepts of denotation and connotation in the sign system was used to examine the denotative and connotative meanings of body movement, image and sound in the Adonko bitters audio-visual ad. A semi-structured interview guide was used to interview six respondents, which confirmed Barthes' approach of the analysis of concrete sign vehicles as vehicles of culture and ideology or myth which reinforces society's expectations of male gender. It is also revealing, from the discussion that media play contributory roles in strengthening further the assumption that women are 'objects' meant to please men. It emerged from the selected signs that women were portrayed as dependent beings, contrary to the perceptive societal stereotypes. The authors conclude that Adonko bitters audio-visual ad conveys a message contrary to society's expectations regarding gender roles. The media must make conscious efforts to redirect discussions around gender stereotyping by highlighting the realities of society. Advertising practitioners as well as advertisers must desist from portraying women in ways that reinforce societal gender stereotyping.
\end{abstract}

Keywords: Adonko bitters; Advertisement; Connotation/Denotation; Gender roles; Audiovisual; Stereotypes. 


\section{Introduction}

Recent upsurge in the number of alcoholic beverages on the Ghanaian market, coupled with the increasing number of advertisements being broadcast in the digital space, is an open secret. There have also been series of campaigns seeking to promote gender equality and health awareness, especially regarding alcohol consumption - Example: Calls for women's political participation (Asuako, 2017); Affirmative action drives (Tsikata, 2009). However, there appears to be issues of gender stereotyping and increase in alcohol consumption. Different kinds of bitters keep flooding the Ghanaian market, and these come along with advertisements that try to persuade bitters lovers to purchase and use. Advertisements are powerful tools which possess the ability to change people's perspectives, shape people's opinions, and/or reinforce social stereotypes (Wolska, 2011).

Women's roles in advertisements have been topical and controversial topic for discussion for years. How women are presented in the media is important to consider because of how the media is seen to be reinforcing gender stereotypes in societies. Differences in gender between men and women are based on social but not biological differences (Ramkissoon and Nunkoo, 2012). The expectations of men and women are different in patriarchal societies such as Ghana, where boys and young men grow up with the knowledge that they hold all the power, hence decision making is always the preserve of men. Acts of masculinity are for men while women are to act in 'feminine' ways. If a man acts in a feminine way, he is referred to as a 'woman' and the vice versa. Culturally, men and women are assumed to uphold two extreme sets of traits where on one hand, men often represent the dominant group, hence, can regulate norms and rules. Positive traits such as being strong, active, independent and rational are attributed to men. On another hand, women are viewed as the suppressed/oppressed group hence negative traits such as being passive, weak, dependent and emotional are attributed to them. These roles are however, socially constructed and constantly reinforced by the media, through family and other social gatherings. The media is profoundly culpably involved in the process of defining and framing gender (Aalberg \& Jenssen, 2007; Media Awareness Network, 2009; ISSER Report, 2015/16). The ISSER report notes a pattern as far back as the 1990s by Neto and Pinto (1998), where women are more commonly featured in adverts promoting domestic products (e.g. soap/detergents, food and medicine) and less likely represented in the perceived masculine products (e.g. technology, construction and financial/insurance products). Media have been said to "provide us with models for behaviour by reflecting and reinforcing existing beliefs and attitudes" (Media Awareness Network, 2009).

According to Graham (1971) as cited in ISSER Report (2016), women are less likely than men to enter school and, if they did, would receive an inferior education that emphasized domestic over the technical skills that might gain them access to the then burgeoning formal sector. Beyond the numbers, the report identifies instances of stereotypical portrayals of women, for instance, in a Vodafone Ghana advert promoting a mobile airtime offer; the "Men Only" deodorant spray ad, where masculine acts are attributed to men, thereby connoting that some things are the preserve of men only. There is also a tendency, albeit to a limited extent, to project women as reward for men's use of certain products. Evidence comes from an 'Alomo Bitters Apuutoo' advert, in which a man misses the chance to attract a beautiful woman because he is drinking the wrong alcoholic beverage (ISSER report, 2016). Then emerges the issue of meanings embedded in how gender is portrayed in the media especially in alcoholic beverage advertisements. Alcohol ads have been analyzed by 


\section{World Conference on SOCIAL SCIENCES}

\section{8-20 October, 2019 BUDAPEST, HUNGARY}

researchers on several dimensions, including Discourse Analysis (Ho, 2009), and textual analysis (Keyes, et al, 2010).

This paper examines how gender is portrayed in "Adonko Bitters" audio-visual advertisement in Ghana and discusses the underlying gender ideologies, using semiotic analysis. Also, the authors investigate people's awareness about gender issues and how they understood the messages in the Adonko bitters ad by conducting in-depth interviews with two bitters consumers; two gender activists/advocates (a man and a woman); and two alcohol/bitters vendors. Their views/opinions and knowledge about the Adonko bitters audiovisual ad were examined.

Audio-visual advertising can transmit audio and visual content to a mass audience simultaneously. Unlike ads shown on television channels, which are allotted specific times, audio-visual ads posted on YouTube channels are not bound by time, and so are available online and can be downloaded and watched as many times as needed. The use of computer technology is on the rise and this continuously exposes people to a variety of new media sources (Sheldon, 2004). Audio-visual ads serve as forms of communication that break down the traditional barriers of audio only or video only communication to ensure that comprehension is enhanced. Williamson (1978) posits that ideological function of advertisements creates structures of meanings, and these structures of meaning are helpful and influential to structuralist method of analysis. Berger (1998) is of the view that images in advertisements are usually current and these images are constantly changed to be abreast of the times, however, they can also refer to the past as well as the future. Berger's view may mean that advertisements are reflective of changes in society. Courtney and Whipple (1983) say that sexual and erotic images are the single most prominent characteristic of advertising, and Muro (1989) supports this assertion with the belief that sex sells products.

\subsection{Analytical Framework}

Semiotics, as the study of signs, according to Barthes, cited in Hervey (2016) can accommodate any system of signs in any form or substance and limits - images; gestures; musical sounds; and objects; these signs make up a system of signification. Barthes' tradition focuses on denotation and connotation of signs. Barthes argues that verbal language is only but one of the many systems of meaning because other systems such as gesture, clothing, architecture and other forms can be analysed like verbal languages.

Semiotics makes use of the term 'sign' to describe how meanings are socially produced; hence a sign has physical form, called the signifier, and refers to something other than itself, called the signified. The signifier is the image while the signified is a concept. Semiotics places emphasis on the fact that our perception of reality is constructed and shaped by the words and signs we are exposed to, in various social contexts. According to Saussure (1974) cited in Hodge (2014) meaning is derived from the differences between signifiers.

\subsubsection{A Sign is the Combination of its Signifier and Signified}

According to Barthes (1964), the signifier is the physical form of the sign as perceived through our senses; an image. The signifier is not a sign of the signified, rather the signifier and the signified work together in an inseparable bond to form a sign. The signifier has a material nature as in sound, object, or image. Barthes' concept of the signifier is an extension of de Saussure's concept, even though Barthes disagrees slightly with Saussure, he agrees that 
it is impossible to separate the signifier from the signified, hence the associative nature of the two (Barthes, 1964). The signified on the other hand is the meaning(s) associated with the sign. The signified is not a thing, rather a mental representation of things, having a psychological and abstract nature that is deciphered through denotation, hence Barthes' concept of denotation.

According to Barthes (ibid) signs can signify, or name or denote different aspects of our experiences of the world. For instance, the word 'red' denotes a certain part of the colour spectrum, which can be differentiated by language from other parts such as 'blue' or 'yellow'. Barthes claims that every ideological sign results from two interconnected sign systems: the first system being descriptive, thus the signifier image and the signified concept combines to produce a denotative sign, which he refers to as the first level of signification. The second level of signification is connotation. The connotative sign system is a mythic sign that has lost its historical referent, which he refers to as 'form without substance' (Barthes, 1964). We do not just understand signs when we see them, we, make some associations with that sign, and this directs our understanding of the sign. This is what Barthes refers to as connotation. 


\title{
World Conference on SOCIAL SCIENCES
}

\author{
18-20 October, 2019 BUDAPEST, HUNGARY
}

\section{Gender and Stereotype}

Gender, according to Aina (2006:1) refers to "the social relationships between men and women and the way those relationships are made". Zevallos (2014) sees gender as the determination and management of sex categories; the cultural meanings attached to the roles of men and women; and how individuals perceive their identity as being a man, woman or other gender positions within a society. She expatiates that gender involves social norms, attitudes and activities that a given society considers appropriate for each sex. Fricker (2007) considers a stereotype as a widely held and recognized association between a social group and an attribute(s). Stereotypes can be positive, negative, or neutral, derogatory, complimentary or indifferent depending on the context in which they are being used. Blum (2004) on the other hand describes stereotypes as rigid, false generalizations about a group.

As a resultant effect, stereotypes mostly take the negative attributes that end in discrimination, stigma attributions, and inequalities. This, according to Beeghly (2014), exposes the vulnerable members of society, mostly, women and the poor. Significantly, the words "rigid" and "false" in Blum's description erupts my interest. Rigidity in stereotypes in the sense that when people hold a stereotypical idea about a group, they internalize it and tend to ignore the other group members who do not share that stereotype; in essence people tend to lump together, every member of a group; which makes the stereotypical thinking false since it may not apply to all group members. Therefore, generalization should not be entertained. This is just fair, since no diverse individuals in a group would measure same on any identified attribute. Blum (2004) therefore calls the generalization as bad stereotypes. In the first place, all members of the group are considered alike and treated as such, if one does not see members as individuals. Secondly, stereotype tends to mask the internal diversity of group members, such as seeing members of a given group through an attribute, for example, women seen as dependent. Lastly, moral distancing, according to Ngulube (2018), is the viewing of members of a stereotyped group more different from other groups than they truly are. This does not help people and groups to see themselves as equals.

From inference, the generalization often presents a form of injustice; reason being that individual members of a stereotyped group are judged based on a stereotype which does not apply to those individuals in that group, considering that people often make use of stereotypes when making credibility judgements of other people (Fricker, 2007). For example, women being stereotyped as dependent put women at risk for being denied the chance to make decisions on their own or be denied leadership roles/opportunities. According to Crespi (2004) males and females are often stereotyped based on the characteristics they are expected to possess due to their biological nature. It is, however, not fair to link biological traits with stereotypical gender roles since this does not favour anyone, because for instance, females are usually stereotyped by traits which tend to silence them by limiting their ability to make decisions and choices concerning their lives, family, and society at large.

Lindsey (2005), cited in Ngulube (ibid), opines that stereotypes that target females can result in sexism - the belief that the female status is inferior to the male. She further expands that such belief is perpetuated by systems of patriarchy, male-dominated social structures whose norms operate and have become the standard to which people adhere, throughout all social institutions. Sexism leads to the oppression of women and thus, the limitation of social and economic opportunities. Consequently, Manne (2015) on misogyny, opines that patriarchal social structures and the ideology that governs them work to make women into men's attentive 
social subordinates and conceal many of the forms of dominance and power which men have over women. Thus, the general expectation within such a society is that women must, without hesitation function in social roles which serve men's interests.

\subsection{The Gender Policy of Ghana}

The Ghana government, in its quest to fulfil its gender mandate by promulgating a national policy for addressing gender related inequalities and injustices approved a "National Gender Policy" (Grebe, 2015). Thus, government responded, among other initiatives, to a directive requesting all government ministries to formulate gender policies that led to gender issues being mainstreamed into public affairs and that comprises a significant boost in the effort to promoting gender balance, which could increase the participation of women in decision making (Grebe, 2015). The gender policy seeks to empower the vulnerable groups particularly, women, children, and people with special needs.

Significantly, this policy document is supposed to see to the achievement of gender equality as the attainment of human rights and a requirement for sustainable development. The policy views gender equality and women empowerment strategies as a way of reducing social injustices among women and men, improving health standards, and enhancing the efficiency of public and private sector investments and national finance (Grebe, 2015).

Therefore, the main objective of the National Gender Policy is to improve the social, legal, civic, political, economic, and sociocultural conditions of the people of Ghana-particularly women, girls, children, the vulnerable, people with special needs, persons with disabilities, and the marginalised-by mainstreaming gender equality concerns into the national development process (ibid). Further, the Policy developed five broad objectives as policy commitments and strategies, which are expected to lead to the achievement of the main objective. The core issues governing these broad objectives are women's empowerment, women's rights and access to justice, leadership and accountable governance for women, economic opportunities for women, and gender roles and relations.

The policy document highlights issues of concern on which stakeholders in the sector are expected to take strategic action (Grebe, 2015, p. vii). These include:

- Unequal access to social, economic power and justice, including a lack of respect for and inadequate protection and promotion of the human rights of women and girls

- Inequalities between women and men in sharing of power and decision-making at all levels and in dealing with all kinds of conflicts, insecurities, and threats on women and girls.

- Stereotyping and persistent discrimination against women and girls that manifest in negative gender relations, as well as value for gender roles and responsibilities with severe implication for maternal health and mortality. The policy document notes, however, that despite the country's continued progress in promoting gender equality at all levels, mostly evident in urban areas, inequities still exist in the social structure despite efforts to get rid of them.

\section{Method}

The first step was downloading Adonko bitters audio-visual ad from the Adonko Bitters YouTube channel on the Internet. Items were coded based on Barthes' denotation and connotation system of the sign within the semiotics theory. Adonko Bitters ad was selected 
for the study because it is among the most popular alcoholic beverage (especially bitters) audio-visual ads in Ghana. This ad was chosen to examine the meanings, using Barthes' denotative and connotative concepts of the sign. Secondly, the authors observed the visual messages in the advertisement such as shape, body movements and image. Third, the authors listened to the verbal messages, which were applied as the background song of the ad. Finally, we conducted in-depth interviews with the following respondents: two bitters consumers, who have patronized alcoholic beverages, specifically adonko bitters for more than seven years (We believe their responses will be reliable, owing to their experience); two gender activists/advocates (a man and a woman); and two alcohol/bitters vendors. Their views/opinions as well as knowledge about Adonko bitters and the Adonko bitters audiovisual ad were taken to corroborate the analysis, in conformity. The data collected were analysed descriptively and qualitatively based on the theory of semiotics. The verbal signs, visual signs in the advertisement as well as interviews were analysed based on Barthes' concept of the sign (1964).

\subsection{Content of advertisement}

This section presents the contents of the adonko bitters audiovisual ad, the storyline of the ad and other effects/elements are also presented, with the latter put into brackets. (Setting: Outdoor, under a tree. A man, an ice chest full of bottled adonko bitters drinks, some ice cubes and 15 ladies, each holding Adonko bitters appear).

\subsubsection{Adonko Bitters Ad (produced by SAMDACKUS Initiative)}

\section{https://youtu.be/kurb-uUDPAQ}

A man is standing (wearing white long sleeves shirt, a black flying tie, a black cowboy hat with some grey stripes, a black trouser, and a white pair of shoes, holding a transparent disposable cup to his mouth, with what appears to be Adonko bitters in the cup) and to his left hand side is a lady (wearing a white singlet with a cloth wrapped around her waist, she wears a "natural" braided hair, with a broad smile on her face) holding a bottle of Adonko Bitters and a transparent plastic cup half-filled with Adonko bitters. Behind the man and the lady are about 15 ladies, each of them holding a bottle of Adonko bitters.

The ad begins with a background song in a male voice (the man appears to be miming the male voice in the song) "me twa bi a na magyina me nan so; ma twa bi nti mennye meho aduro; me nom biaa na magyina pintin; ma nya ahuondin nti mensuro hwee”, (I am able to stand on my feet when I drink some; I have drunk some so I don't patronize any medication) the 15 ladies begin to dance to the song.

The man takes a sip (camera focuses on the cup and the feet of the man) of Adonko bitters from the cup; he makes some quick moves with his feet (rhyming with the words in the song - I stand on my feet) and adjusts his cowboy hat. The lady beside him makes a gesture towards the man's feet, probably because the shuffled his feet specifically towards the location of his zip, and she wears a broad smile. The man turns back towards the ice chest behind him and bends as if he was picking something from the ice chest. The lady also bends and holds the cover of the ice chest and smiles at the man. Then we see the man on a swing being swung by two ladies. Later in another scene, we see the lady on the swing (Adonko twi name for a swing) being swung by the male. Could it be mere coincident that the lady 
goes on the swing after the man had done it? Or is it a deliberate action by the advertiser to send a message across?

\section{Results and Discussion}

The discussion is based on the following themes: stereotypical portrayals of gender; stereotypical images of the relationship between male and female; media's contribution to the projection of societal ideologies of gender roles.

\subsection{Stereotypical portrayals of Gender in Adonko audio-visual ad}

This section discusses gender in relation to body movement and representation. Gender is portrayed stereotypically in the Adonko Bitters ad, right from the first scene. The image of man as portrayed in the adonko bitters ad appears stereotypical. In the first place, the ad projects one man surrounded by 15 ladies. One may argue that it is a plus for the media since more females are represented. However, it is also genuine to question the type of representation considering the role(s) played by each gender in the ad. We believe that more females were presented in the ad to connote the feeble and vulnerable ideological stereotype of how the female gender is perceived by society, especially patriarchal societies such as Ghana - women are considered weak in strength as compared to men, women are vulnerable as compared to men, and women are dependent, hence women need to be supported by man/men. It may also be a reflection of the gender ratio in Ghana - more women than men. This reinforces society's expectations of man's behaviour(s). According to Barthes' first level of signification (denotation), this scene denotes that every man who patronizes Adonko Bitters will be loved by many ladies (surrounded by many ladies). However, the same scene connotes the ideology that society allows a male to love or marry more than one female, hence reinforces the idea that society perceives females as inferior to males. It also reflects the ideology that more females are needed to equate what one male can do. The scene presents all the females surrounding one male as focusing their attention on the male; watching each move he makes as if they are in expectation of his approval. Again, this signifies that females are meant to please males. These meanings conform to Barthes' second level of signification - connotation. These are messages that are hidden, and it takes deeper reasoning to grasp the meaning.

\subsection{Stereotypical images in the media of the relationship between male and female}

The media is known to portray men and women mostly in accordance to how society views gender. The following themes demonstrate how media reflect and promote society's arrangement between male and female.

\subsubsection{Men at the center of attraction}

The Adonko ad seems to focus more attention on the male figure. In the ad, the camera zooms on the man's face, to reveal his facial expression and the cup in his hand as well as how he drinks the content. This may be because the Adonko bitters is meant to be consumed predominantly by men (Picture 3). Each of the man's moves is given special attention through camera zooms and projection of intense attention on him by the several females who surround him. When the man took a sip of the drink, the lady appeared to look sternly, and when he 
made a quick move with his feet, turns to the ice chest, the lady had to wait for him to show the way.

\subsubsection{Men are rulers and women are servants to men}

The ad presents the male gender as a ruler while sharply portraying the female gender as servants, and not just servants but servants to the male gender. In the ad, aside from the 15 ladies almost encircling the only male, there was one lady who was so close to the man. She appears to be playing a 'special assistance' role to the man. She presented the transparent cup containing adonko bitters to the man. After the man had taken a sip, he hands over the cup to her. To us, this image appears 'normal' since the society in which the ad was created and aired accepts the fact that man is superior to woman; hence woman must play servant roles to man. This projection conforms to the stereotypical ideology that women are inferior to men. Media seem to be reinforcing this notion by projecting the gender roles acceptable by society. There is an Akan saying that 'if a woman buys a gun, she keeps it in a man's hut'. The lady's readiness to assist the male character is a signifier of servanthood.

\subsubsection{One gender is for another's pleasure}

The female characters in the ad were portrayed as 'objects' for man's pleasure. All the female characters were holding a bottle each of Adonko bitters. The lady very close to the male character had in her hands a transparent plastic cup with adonko bitters as its content. However, she did not drink but rather gave it to the man to drink while she looked on and appeared to be nodding her head in appreciation of the fact that the man drunk what she served him. Connotatively, this could mean that the woman expected the man to satisfy himself with the Adonko bitters, so that he in turn could satisfy her sexually. Hence, she nodded probably, in anticipation of the pleasure she would attain. She again follows the man to the ice chest, bent down to help and finally helped to swing the man on the seesaw/pendulum. This connotes that women must do all to please men. It appears the adonko bitters is largely for male, however, there were more female representations in the ad. Even though, this may be viewed as a deliberate attempt by the advertiser to project society's ideology of presenting gender, it may also be a way of going against society's expectation.

\subsubsection{Media's projection of society's gender roles}

At the heart of all these is how media tend to project gender, thereby reinforcing stereotypes held by society. In-depth interviews were conducted to find out how people receive and perceive the media's role projecting or otherwise, gendered ideologies. Six respondents comprising two adonko bitters consumers; two gender activists/advocates (a man and a woman); and two alcohol/bitters vendors were interviewed. All the two adonko bitters consumers admitted that the adonko bitters ad was 'attractive' due to how many ladies were dancing to the background song. One went further to state that he was particularly fascinated by how the ladies swung the man right after he took the drink. The other man said he trusted the efficacy of the adonko bitters. When asked whether they found anything wrong with the fact that the drink appears to be for men, but the ad has more females, one claimed he found absolutely nothing wrong with it. Clearly, it is a revelation that the ideologies are generally naturalized and become "common sense" shared by certain groups of people (Burton, 2005: 351). He went further to state that there was nothing wrong since the adonko is supposed to help men to satisfy their women in bed. This view expressed puts men in the servitude position -as objects for the satisfaction of women sexually through the consumption of 
Adonko bitters, thereby illuminating the role of females, thus helping men so they in turn satisfy the women. He could not confirm whether drinking adonko bitters has endeared him to his wife the more. For the two vendors - one male (34 years of age) and a female (30 years old); the man did not see anything wrong with how gender is portrayed in the adonko ad. He said women are to 'make men happy' and serving men was part of the process. He said there is nothing wrong even if a woman appears to worship a man and that he loved the adonko ad. He said that a lot of men patronize the adonko bitters; some drink adonko bitters as appetizers. The female vendor also tends to agree with the male vendor. She said she would be happy to serve her husband in anyway and form, once that will make him happy and enhance his sexual performance. This belief of the female further confirms the view that men may serve as tools for women's pleasure, once the men consumed Adonko bitters. The male gender activist was not pleased with how media tend to portray gender even in the twenty-first century. He believed the media must try to shape the dialogue when it comes to gender issues. He liked the song in the Adonko bitters ad; however, he did not like the way many ladies were paraded around one man in the ad. The female gender activist was appalled about the way gender played out in the Adonko bitters ad. She believed the media must do more to educate society about the "bad" stereotypical portrayal of women in advertisements (Appendix A).

\section{Conclusion and Recommendation}

The paper considered only one 'bitters' ad in Ghana. Therefore, generalization of the findings must be done with caution; hence more alcoholic (bitters) ads can be analysed in subsequent study. Despite this, the authors conclude that even though males are usually seen and believed to be strong, independent and courageous by society, the Adonko bitters ad portrayed the male figure otherwise - as sexual tools for women's sexual satisfaction. The female figure was rather projected subtly as beneficiaries - since men who consume Adonko bitters, do so with the aim of being able to satisfy women. This reveals that the stereotypical thinking of women being portrayed as objects or tools for men's satisfaction remain mere perceptive-stereotypes and is not reflective of the realities. The media must make conscious efforts to redirect discussions around gender stereotyping by highlighting the realities of society. Advertising practitioners as well as advertisers must desist from portraying women in ways that reinforce societal gender stereotyping. 


\section{References}

[1] Aalberg, T. \& Jenssen, A.T. (2007). Gender stereotyping of political candidates: An experimental study of political communication, Nordicom Review, 28, 17-32.

[2] Aina, O. I. (2006). Sex versus gender. Paper presented at a workshop on Gender Disaggregation at the Obafemi Awolowo University, Ile-Ife.

[3] Asuako, J. (2017). Women's political participation - A catalyst for gender equality and women empowerment in Ghana. UNDP - Ghana.

[4] Berger, J. (1998). Ways of Seeing. London: Penguin.

[5] Beeghly, E., M. (2014). Seeing difference: The ethics and epistemology of stereotyping (Doctoral Dissertation). Available: http://digitalassets.lib.berkeley.edu/etd/ucb/text/Beeghly_berkeley_0028E_14475.pdf

[6] Blum, L. (2004). Stereotypes and stereotyping: A moral analysis. Philosophical thesis, 33 (3), 251-289.

[7] Burton, G. (2005). Media and Society: Critical Perspectives. Berkshire: Open University Press.

[8] Crespi, I. (2004). Socialization and gender roles within the family: A study on adolescents and their parents in Great Britain. MCFA Annals, 3.

[9] Coutney, A. E. \& WhippIe, T. W. (1983). Sex stereotyping in advertising. Lexington, MA: D. C.

[10] Grebe, E. (2015). The evolution of social protection policy in Ghana's 'Fourth Republic': Contributory social insurance reform and limited social assistance for the 'extreme poor'under NPP and NDC governments, 2000-2014.

[11]Fricker, M. (2007). Epistemic injustice: Power and the ethics of knowing. Oxford University Press.

[12] ISSER Report, (2015/16). Available: http://isser.edu.gh/index.php/annual-report/227isser-2015-2016-annual-report

[13] Hervey, S. (2016). Semiotic perspectives. Routledge.

[14]Ho, V. W. L. (2009). Is woman or liquor being sold? -Gender analysis of alcohol TV commercials in Hong Kong.

[15]Hodge, B. (2014). Social semiotics. In the Routledge Companion to Global Popular Culture (pp. 58-66). Routledge.

[16]Keyes, K. M., Hatzenbuehler, M. L., McLaughlin, K. A., Link, B., Olfson, M., Grant, B. F., \&

[17]Hasin, D. (2010). Stigma and treatment for alcohol disorders in the United States. American Journal of Epidemiology, 172(12), 1364-1372.

[18]Lindsey, L. L. (2005). The sociology of gender: Theoretical perspectives and feminist frameworks. Gender roles: A sociological perspective, 1-21. 
[19] Manne, K. (2015). What is misogyny? A feminist analysis. unpubl. ms.

[20] Media Awareness Network (2009). APEC-OECD Joint Symposium on Initiatives Among Member Economies Promoting Safer Internet Environment for Children. Singapore.

[21] Muro, M. (1989). Comment: New era of eros in advertising. Morning call, pp. D1, D16.

[22]Neto, F., \& Pinto, I. (1998). Gender stereotypes in Portuguese television advertisements. Sex Roles, 39(1-2), 153-164.

[23] Ngulube, Z. (2018). The influence of traditional gender roles and power relations on women and girls' education and health in northern Ghana (Doctoral dissertation).

[24] Ramkissoon, H. \& Nunkoo, R. (2009). More than just biological sex differences: Examining the structural relationship between gender identity and information search behavior. Available: http://citeseerx.ist.psu.edu/viewdoc/download?doi= 10.1.1.897.2538 $\&$ rep=rep1\&type=pdf on 15th April 2017.

[25] Sheldon, P. (2008). The relationship between unwillingness-to-communicate and students' Facebook use. Journal of Media Psychology, 20(2), 67-75.

[26] Tsikata, D. (2009). Affirmative action and the prospects for gender equality in Ghanaian politics. Abantu, Women in Broadcasting and the Friedrich-Ebert-Stiftung

[27] Williamson, J. (1978). Decoding Advertisements. London: Marion Boyars.

[28] Wolska, M. (2011). Gender stereotypes in mass media. Case study: Analysis of the gender stereotyping phenomenon in tv commercials. Available: http://krytyka.org/genderstereotypes-in-mass-media-case-study-analysis-of-the-gender-stereotyping-phenomenonin-tv-commercials/

[29]Zevallos, Z. (2014) 'Sociology of gender,' The Other Sociologist. Available: https://othersociologist.com/sociology-of-gender/ 


\section{Wㅁㄴ \\ ㄷ 5 S}

World Conference on SOCIAL SCIENCES

\section{Appendices}

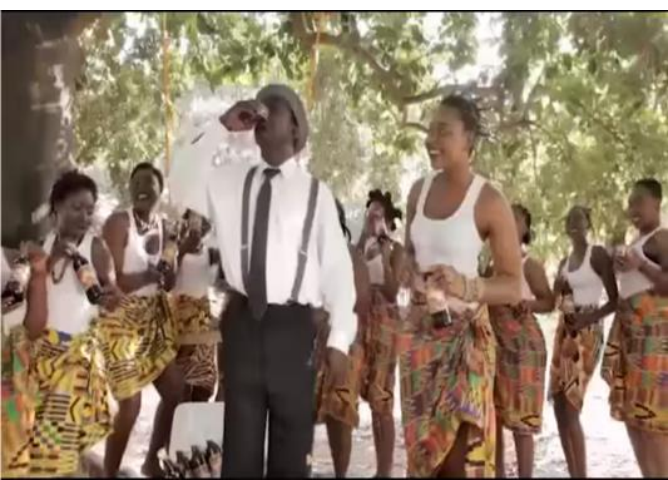

Appendix A

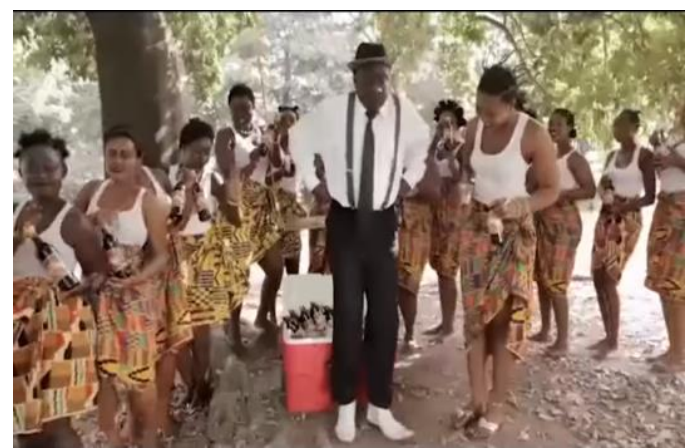

Appendix B

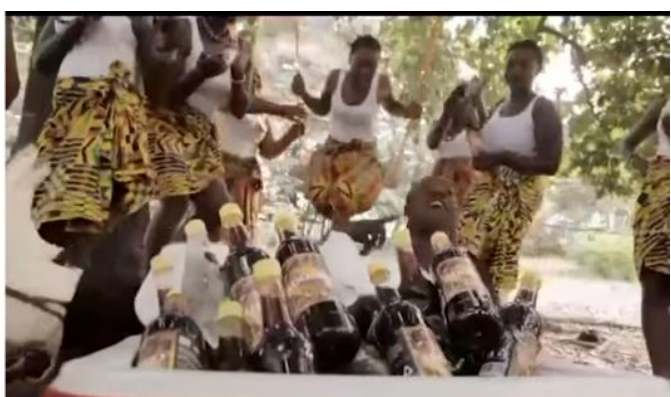

Appendix C

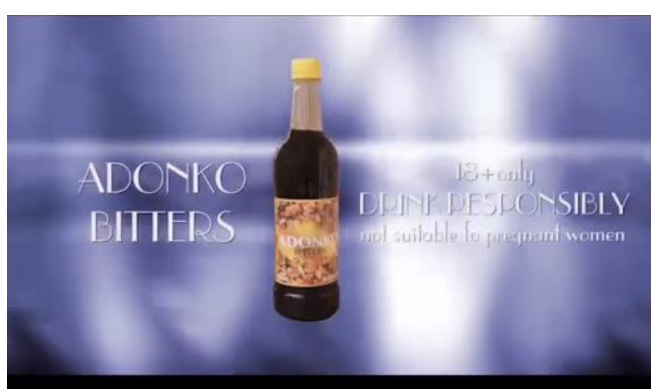

Appendix D 